\title{
VARIAÇÃO ESPACIAL E TEMPORAL DE BAGRES MARINHOS (SILURIFORMES, ARIIDAE) NA BAÍA DE SEPETIBA, RIO DE JANEIRO
}

\author{
AZEVEDO, M. C. C., ${ }^{1}$ ARAÚJO, F. G., ${ }^{1}$ CRUZ-FILHO, A. G., ${ }^{2}$ \\ GOMES, I. D. ${ }^{1}$ e PESSANHA, A. L. M. ${ }^{1}$ \\ ${ }^{1}$ Laboratório de Ecologia de Peixes, Universidade Federal Rural do Rio de Janeiro, \\ Km 47 da Antiga Rodovia Rio-São Paulo, Seropédica, CEP 23851-970, Rio de Janeiro, RJ \\ ${ }^{2}$ Fundação Instituto de Pesca do Estado do Rio de Janeiro - FIPERJ, \\ Praça XV de Novembro, 2, 3o andar, CEP 20010-010, Rio de Janeiro, RJ \\ Correspondência para: Márcia Cristina Costa de Azevedo, Laboratório de Ecologia de Peixes, \\ Universidade Federal Rural do Rio de Janeiro, Km 47 da Antiga Rodovia Rio-São Paulo, \\ Seropédica, CEP 23851-970, Rio de Janeiro, RJ \\ Recebido em 14/04/98 - Aceito em 08/12/98 - Distribuído em 10/09/99
}

(Com 6 figuras)

\begin{abstract}
Spacial and temporal variation of marines catfishes on Sepetiba Bay, RJ.

Marine catfishes (Ariidae) are abundant fishery resource in the Sepetiba Bay, Rio de Janeiro State (Lat. $22^{\circ} 54^{\prime}-23^{\circ} 04^{\prime}$ S ; Long. $43^{\circ} 34^{\prime}-44^{\circ} 10^{\prime} \mathrm{W}$ ), that is considered an important rearing area to a great number of juvenile fish. Artisanal fisheries are important economic activity in the region. Spatial and seasonal distribution and relative abundance of marine catfish, based on the number and weight of fish catched per sample (Catch per Unit Effort $=$ CPUE) were assessed based on 151 otter trawl sampling in seven sampling sites in the Sepetiba Bay, between July 1993 and June 1996. For spatial comparisons, the study area was devised in an inner zone, located in the inner Bay and an outer zone, near to the sea limit. Environmental parameters of surface and bottom water temperature and salinity, transparency and depth were recorded at each sampling. A spatial variation pattern, assessed by multivariate methods, is shown with higher depths and transparencies in the outer bay and lower in the inner bay, while salinity seems to decrease slightly toward the inner bay. Only temperature showed seasonal variation. Five marine catfish species were recorded in the following order of decreasing numerical abundance: Genidens genidens (Valenciennes, 1839), Cathorops spixii (Agassiz, 1829) Sciadeichthys luniscutis (Valenciennes, 1840), Netuma barba (Lacepéde, 1803) and Bagre marinus (Mitchill, 1814).The top four abundant marine catfish occur in higher abundance in the inner Bay, with indication of spatial separation within this area. G. genidens was abundant over all sampling sites in the inner Bay, while $C$. spixii showed a narrower distribution in this area. $N$. barba concentrated near to Guandú River estuary, and S. luniscutis showed an ample distribution over all the Bay. Seasonally was not marked for all species. Strategies of spatial separation may be explaining the coexistence of marine catfish in high abundance in the Sepetiba Bay, which is used as fish rearing area mainly due the low depths and transparencies, favorable conditions to their early life cycle development.
\end{abstract}

Key words: marine catfish, Ariidae, Sepetiba Bay, distribution.

\section{RESUMO}

Bagres marinhos (Ariidae) são os mais abundantes recursos pesqueiros em arrastos de fundo na Baía

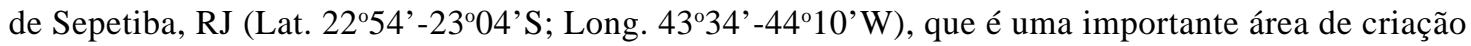
e alimentação de uma grande variedade de espécies de peixes na fase juvenil. Padrões espaciais e sazonais de distribuição dos bagres marinhos, baseados no número e no peso de peixes por arrasto, foram analisados com base em 151 amostragens de arrasto de fundo, em sete locais da Baía de Sepetiba, 
entre julho de 1993 e junho de 1996. Para comparações espaciais da área de estudo, estabeleceu-se como zona interna a região situada no interior da Baía e como zona externa a área com maior influência das águas oceânicas. Juntamente com os arrastos de fundo, foram feitas medições da temperatura e salinidade da água de superfície e de fundo, da transparência e da profundidade. Um padrão de variação espacial baseado nos fatores ambientais, através da análise multivariada, é apresentado com maiores profundidades e transparências na zona externa e menores na zona interna, com pequeno gradiente de aumento de salinidade da zona interna para a zona externa. Somente a temperatura apresentou sazonalidade. Cinco espécies de bagres marinhos foram registradas, na seguinte ordem decrescente de abundância numérica: Genidens genidens (Valenciennes, 1839), Cathorops spixii (Agassiz, 1829), Sciadeichthys luniscutis (Valenciennes, 1840), Netuma barba (Lacépède, 1803) e Bagre marinus (Mitchill,1814). Um padrão de variação espacial na distribuição dos bagres marinhos na Baía de Sepetiba foi apresentado, com as quatro mais abundantes espécies distribuindo-se principalmente na zona interna da Baía, com indicações de separação espacial entre as mesmas. G. genidens foi abundante em todas as estações de coleta da zona interna da Baía, C. spixii apresentou distribuição mais restrita na zona interna e $N$. barba, nas proximidades da embocadura do Rio Guandú, enquanto $S$. luniscutis apresentou ampla distribuição na zona interna e externa da Baía. A sazonalidade não foi marcada para essas espécies. Estratégias de separação espacial podem estar explicando a coexistência em elevada abundância de bagres marinhos na Baía de Sepetiba, que funciona como área de criação desses peixes, os quais encontram nas menores profundidade e transparência da zona interna condições favoráveis para o desenvolvimento de seus ciclos de vida.

Palavras-chave: bagres marinhos, Ariidae, Baía de Sepetiba, distribuição.

\section{INTRODUÇÃO}

A Baía de Sepetiba localiza-se no Estado do Rio de Janeiro entre as latitudes $22^{\circ} 54^{\prime}$ e $23^{\circ} 04^{\prime} \mathrm{S}$ e as longitudes $43^{\circ} 34^{\prime} \mathrm{e} 44^{\circ} 10^{\prime} \mathrm{W}$ (DHN, 1984). É considerada uma importante área de criação e de alimentação de uma grande variedade de espécies de peixes na fase juvenil, sendo a atividade pesqueira um dos suportes econômicos da região. Possui uma ampla faixa costeira de litorais baixos, com influência de pequenos deltas fluviais, planícies de maré e formações típicas de manguezais. Apresenta águas pouco profundas, ricas em nutrientes e matéria orgânica, com fundos predominantes de lama (Costa, 1992).

Os peixes denominados bagres marinhos pertencem à família Ariidae e ocorrem nas zonas litorâneas tropicais e subtropicais, em ambientes marinhos, estuarinos e de água doce, sendo geralmente abundantes em águas costeiras com fundo lodoso e pouco profundas (Araújo, 1988; Andreata et al., 1989). Procuram a embocadura dos rios $\mathrm{e}$ regiões lagunares na época da desova (Figueiredo \& Menezes, 1978; Moyle \& Cech-Jr, 1988). São largamente distribuídos ao longo da costa brasileira, apresentando grande importância econômica na região Sul do país por sua grande contribuição nas pescarias artesanais (Reis, 1986).
Na Baía de Sepetiba, a família Ariidae destacase entre as mais abundantes, contribuindo com cerca de $28,5 \%$ do número e $28,8 \%$ do peso total capturado em arrastos de fundo (Cruz-Filho, 1995). Cinco espécies de Ariidae foram registrados nesta Baía: Genidens genidens (Valenciennes, 1839), Netuma barba (Lacépède, 1803), Cathorops spixii (Agassiz, 1829), Sciadeichthys luniscutis (Valenciennes, 1840), e Bagre marinus (Mitchill, 1814).

Informações sobre distribuição e abundância dessa família são disponíveis em outras áreas costeiras do Brasil. Craig (1980) analisou a distribuição dos bagres marinhos na costa da região de Peruíbe, SP, e Mishima \& Tanji (1981), no complexo estuarino de Cananéia, SP. No estuário da Lagoa dos Patos, RS, Araújo (1988) estudou a distribuição espacial e temporal de três espécies da família Ariidae, e Reis (1986) constatou a grande importância dos bagres marinhos como segundo mais abundante grupo de peixes, contribuindo com $25 \%$ das capturas das pescarias artesanais.

A coexistência em elevada abundância de peixes assemelhados em ecossistema, em que o espaço ou os nichos tróficos são normalmente limitados, pode ocorrer devido ao desenvolvimento de estratégias que permitam a separação espacial ou temporal no uso de tais ambientes por tais espécies, que por apresentarem grande coincidên- 
cia nas estruturas morfológicas podem indicar uma competição, acarretando exclusão das espécies de menor adaptação. Portanto, as espécies aparentadas que vivem na mesma área, em geral, exploram distintos hábitats ou microhábitats (utilização espacial do ambiente) ou são ativas em tempos diferentes (utilização temporal do ambiente).

O presente trabalho visa analisar os padrões espaciais e sazonais de distribuição de quatro espécies de bagres marinhos da Baía de Sepetiba, bem como, investigar como os padrões encontrados estão relacionados com as variáveis ambientais.

\section{MATERIAL E MÉTODOS}

Cento e cinqüenta e uma amostragens de arrasto de fundo foram realizadas em sete estações de coleta na Baía de Sepetiba, entre julho de 1993 e junho de 1996. As amostragens foram mensais no período de julho de 1993 a julho de 1994 (primeiro ciclo anual), e bimestrais no período de julho de 1994 a junho de 96 (segundo e terceiro ciclos anuais).

Os arrastos de fundo foram realizados por arrasteiro, utilizado na pesca comercial na Baía, apresentando $12 \mathrm{~m}$ de comprimento, provido de rede de arrasto de fundo com portas (otter trawl), com malha de $12 \mathrm{~mm}$ na região do saco e abertura de boca de $8 \mathrm{~m}$. Os arrastos tiveram duração padronizada de $30 \mathrm{~min}$., velocidade de 2 nós, cobrindo uma extensão de aproximadamente $1,5 \mathrm{~km}$, sendo realizados em direção contrária à corrente. A seqüência de amostragens nas estações foi aleatória.

Para comparações espaciais da área de estudo, considerando-se uma formação de ilhas na parte oeste da Baía, estabeleceu-se como zona interna a região situada no interior da Baía e como zona externa a área com maior influência das águas oceânicas. Três estações de coleta foram definidas na zona externa (1 - Laje das Enxadas; 2 - Ilha do Socó; 3 - Ilha Bonita) e quatro na zona interna (4 - Costa do Guandú; 5 - Canal da Restinga; 6 Meio da Baía; 7 - Fundo da Baía) (Fig. 1).

As seguintes variáveis ambientais foram tomadas em cada amostragem: temperatura e salinidade para a água de superfície e de fundo, transparência da água e profundidade. Utilizouse garrafa do tipo "Van Dorn" modificada para a coleta de água de fundo. A temperatura foi medida através de termômetro com coluna de mercúrio com precisão de $0,1^{\circ} \mathrm{C}$ e a salinidade, com salinômetro óptico marca Erma Tokio, com precisão de 0,5 partes por mil (\%o). A transparência da água foi medida através de um disco de Secchi com graduação em centímetros, e a profundidade com profundímetro, também com graduação em centímetros.

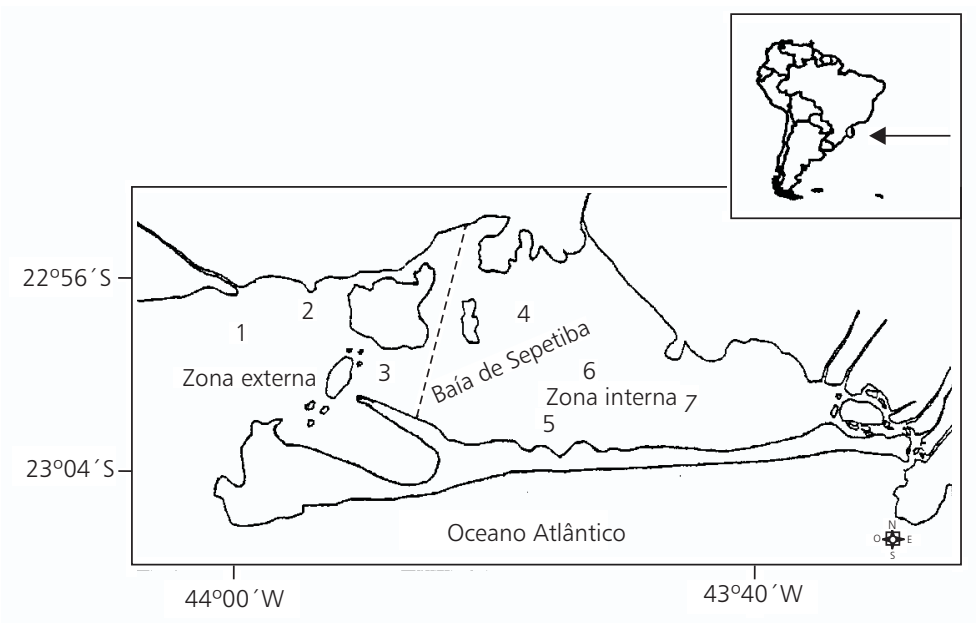

Fig. 1 - Área de estudo - Baía de Sepetiba, RJ, com indicações das estações de coleta na zona externa: 1 - Laje das Enxadas; 2 - Ilha do Socó; 3 - Ilha Bonita; e na zona interna: 4 - Costa do Guandú; 5 - Canal da Restinga; 6 - Meio da Baía; e 7 - Fundo da Baía. Escala: 1: 400.000. 
Os peixes coletados foram separados por espécie, pesados (em gramas), contados e medidos (comprimento total $-\mathrm{mm}$ ) da ponta do focinho até o lobo mais longo da nadadeira caudal. Parte do material foi fixado em formol à $10 \%$ e, posteriormente, conservado em álcool à $70 \%$. A identificação foi feita segundo Figueiredo \& Menezes (1978) e o material testemunha depositado na Coleção Ictiológica do Laboratório de Ecologia de Peixes da Universidade Federal Rural do Rio de Janeiro.

A abundância relativa das espécies foi avaliada através do número de peixes por arrasto (CPUE) e do peso dos peixes por arrasto (biomassa). Os requisitos de normalidade e a homocedasticidade (Sokal \& Rohlf, 1981) para a análise dos dados bióticos e abióticos foram obtidos através da transformação logarítmica $\log (x+1)$ e $\log (\mathrm{x})$, respectivamente, em que Log é o logaritmo na base 10 , e x é o valor não transformado.

As variações espaciais foram avaliadas considerando-se as estações de coleta. Para o critério de sazonalidade (estações do ano), os meses de amostragens foram considerados no seguinte agrupamento: inverno (junho, julho e agosto), primavera (setembro, outubro e novembro), verão (dezembro, janeiro e fevereiro) e outono (março, abril e maio).

As descrições dos padrões espaciais e temporais das populações de bagres marinhos e dos parâmetros ambientais foram feitas através do uso combinado das técnicas estatísticas multivariadas de análise fatorial de componentes principais e da análise de agrupamento (Mardia et al., 1979; Gauch, 1982; Legendre \& Legendre, 1983). Os dados foram agrupados através do Método de Ligação pela Média Não-ponderada (UPGMA), e como medida foi utilizada a distância Euclidiana ao quadrado.

Os grupos formados pela análise de agrupamento foram sobrepostos no gráfico formado pelos dois primeiros componentes principais, visando interpretar o relacionamento entre as amostras codificadas através dos correspondentes meses (padrão temporal) e estações de coleta (padrão espacial).

A Análise de Variância foi utilizada para comparar médias dos dados bióticos (CPUE e biomassa) e abióticos (variáveis ambientais) entre os grupos formados pela análise de agrupamento. Para determinação de quais médias são significativa- mente diferentes, sempre que a hipótese nula foi rejeitada, utilizou-se o Teste de Diferenças de Médias de Tukey, em nível de confiança de $95 \%$ $(\mathrm{p}<0,05)$.

\section{RESULTADOS}

\section{Variáveis ambientais}

A classificação hierárquica das 151 amostragens através da análise de agrupamento apresentou quatro grupos diferentes com distância Euclidiana reescalonada menor que 5\%. O dendograma codificado por estações de coleta (Fig. 2) apresentou nos Grupos I e II as estações de coleta da zona interna Costa do Guandú $(E s t=4)$ e Fundo da Baía (Est =7). O Grupo III corresponde as estações da zona externa Laje das Enxadas $($ Est $=1)$, Ilha do Socó $($ Est $=2)$ e Ilha Bonita $($ Est $=3)$; e o Grupo IV apresentou maior incidência das estações da zona interna Canal da Restinga $($ Est $=5)$ e Meio da Baía $($ Est $=6)$. Esse mesmo dendograma codificado pelos meses de amostragem não apresentou predominância de um determinado mês nos grupos formados.

Dois componentes foram obtidos pela análise fatorial de componentes principais com autovalores excedendo 1,0 e explicando $65,6 \%$ da variância total. O Componente I apresentou maior contribuição da profundidade e da transparência e, em menor escala, da salinidade, explicando $35,7 \%$ da variância total, enquanto que o Componente II apresentou maior contribuição da temperatura de superfície e de fundo, explicando $29,8 \%$ da variância (Tabela 1).

O diagrama dos Componentes I e II das amostragens codificadas por estação de coleta (Fig. 3), separou espacialmente as estações ao longo do Componente I, situando de um lado (esquerdo) as estações de menor profundidade e transparência (Grupos I e II da análise de agrupamento) e do outro (direito), as estações de maior profundidade e transparência (Grupos III e IV da análise de agrupamento).

Esse mesmo diagrama, codificado pelos meses de amostragem (Fig. 4), não apresentou ao longo do Componente I um padrão temporal definido. Já no Componente II, o grupo de meses referentes as estações do verão e outono são apresentados na parte superior do diagrama, em oposição ao grupo formado pelos meses do inverno e primavera, na parte inferior do diagrama. 


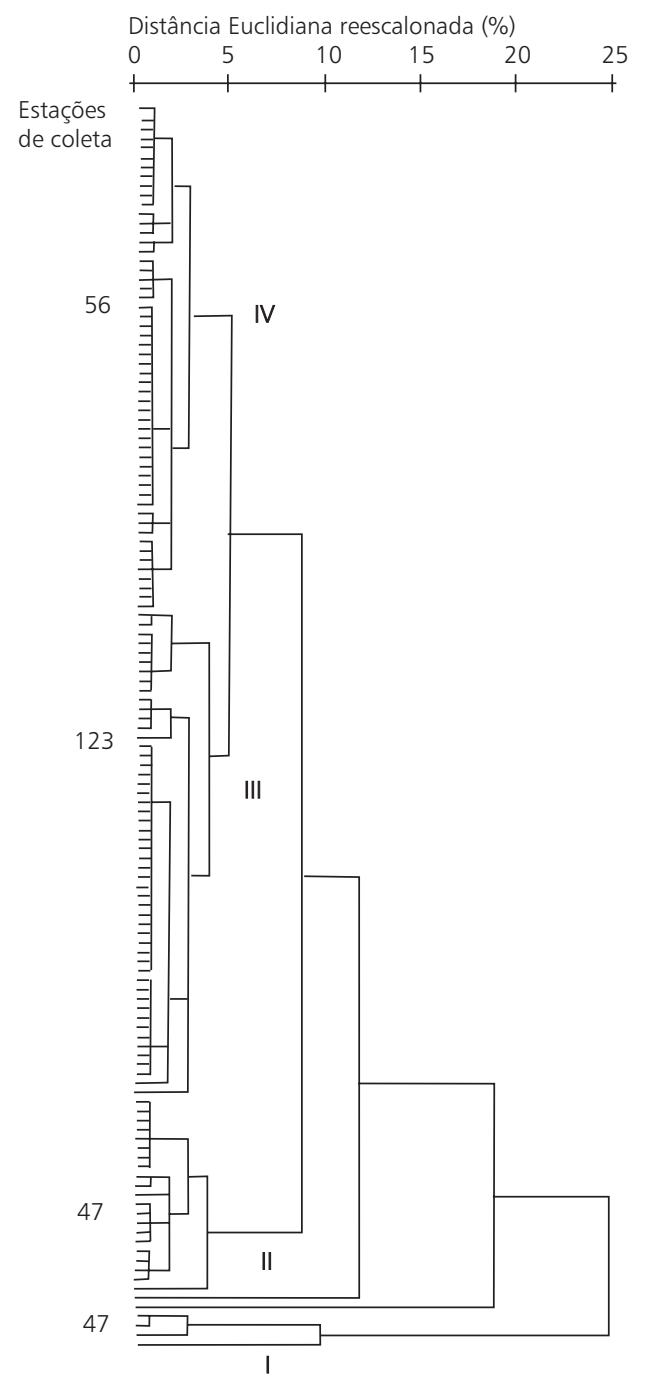

Fig. 2 - Agrupamento hierárquico de fatores ambientais em amostras por estações de coleta na Baía de Sepetiba, RJ, entre 1993/1996. Legenda das estações de coleta conforme metodologia.

\section{TABELA 1}

Componentes principais das variáveis ambientais da Baía de Sepetiba, RJ.

\begin{tabular}{|c|c|c|}
\hline Variáveis ambientais & Componente I & Componente II \\
\hline Temperatura de superfície & 0,05 & 0,95 \\
\hline Temperatura de fundo & $-0,13$ & 0,92 \\
\hline Salinidade de superfície & 0,59 & $-0,12$ \\
\hline Salinidade de fundo & 0,51 & $-0,36$ \\
\hline Transparência & 0,80 & 0,25 \\
\hline Profundidade & 0,85 & $-0,06$ \\
\hline Autovalores & 2,14 & 1,79 \\
\hline Variância explicada (\%) & 35,7 & 29,8 \\
\hline
\end{tabular}




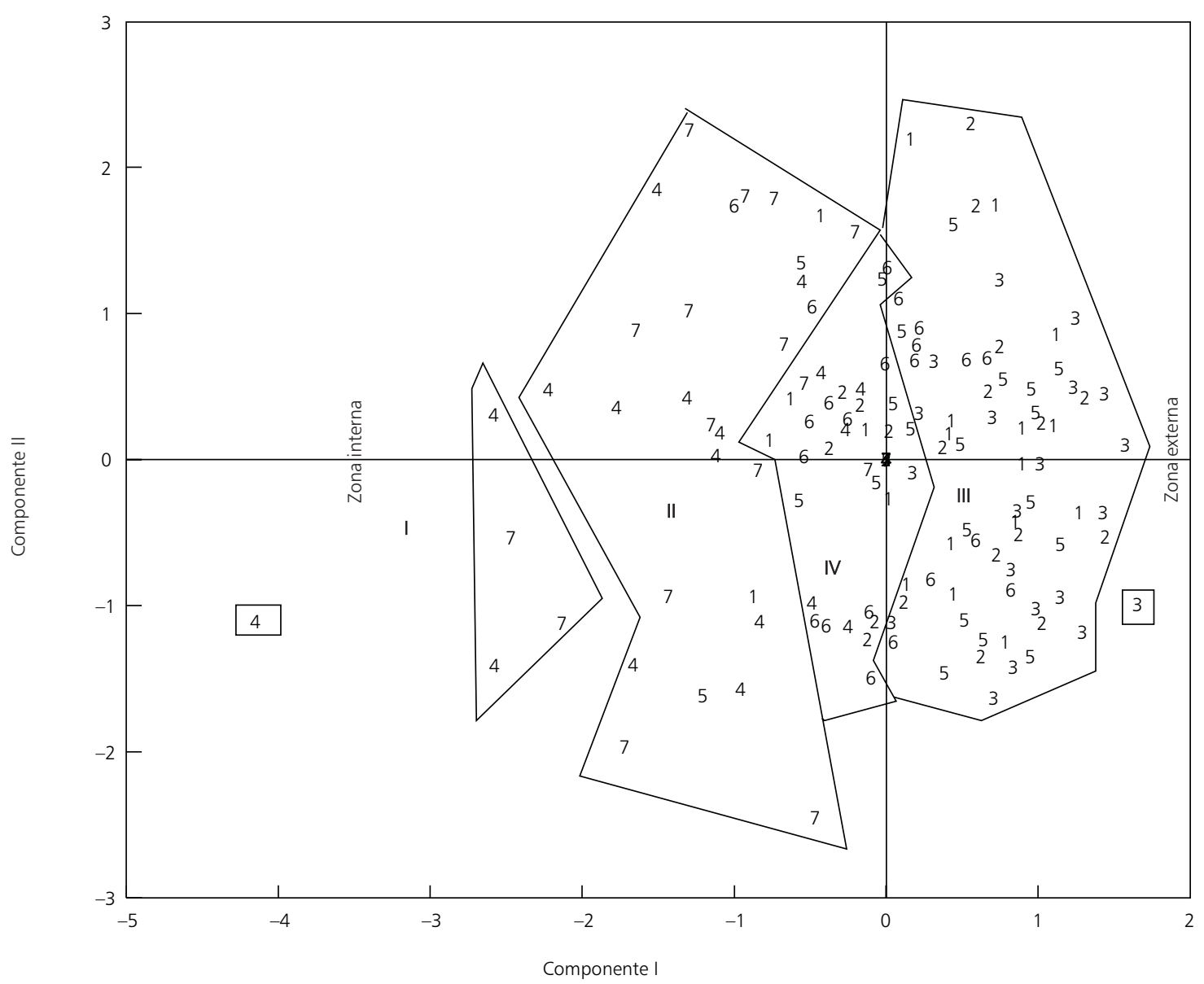

Fig. 3 - Diagrama de ordenação nos dois primeiros componentes principais para as amostras dos fatores ambientais, codificadas por estação de coleta na Baía de Sepetiba, RJ.

O Componente II, que apresenta maior contribuição da temperatura da água de superfície e de fundo, corresponde à sazonalidade das variáveis ambientais. A análise de agrupamento coincidiu com o Componente I da análise de componentes principais, determinando apenas a variação espacial das variáveis ambientais.

\section{Padrões de distribuição espacial e temporal}

A classificação hierárquica das 151 amostragens de abundância em número e peso das quatro espécies de bagres marinhos, através da análise de agrupamento, apresentou seis grupos diferentes com distância Euclidiana reescalonada à $10 \%$. Os Grupos I, II e III corresponderam no dendograma codificado por estações de coleta às estações da zona interna da Baía (Fig. 5). Os Grupos IV e V corresponderam às estações da zona externa e interna, predominando as estações da zona interna; e o Grupo VI apresentou maior incidência das estações da área externa. Esse mesmo dendograma codificado pelos meses de amostragem apresentou os vários meses incluídos nos diferentes grupos, sem a predominância de um determinado mês.

Três componentes principais foram apresentados pela análise fatorial de componentes principais da abundância dos bagres, com autovalores excedendo 1,0 e explicando 83,9\% da variância total (Tabela 2). O Componente I apresentou maior contribuição de $N$. barba e G. genidens, explicando $48,4 \%$ da variância total; o Componente II apresentou maior contribuição de $C$. spixii, explicando $21,2 \%$ da variância; e o Componente III apresentou maior contribuição de $S$. luniscutis, explicando $14,3 \%$ da variância. 


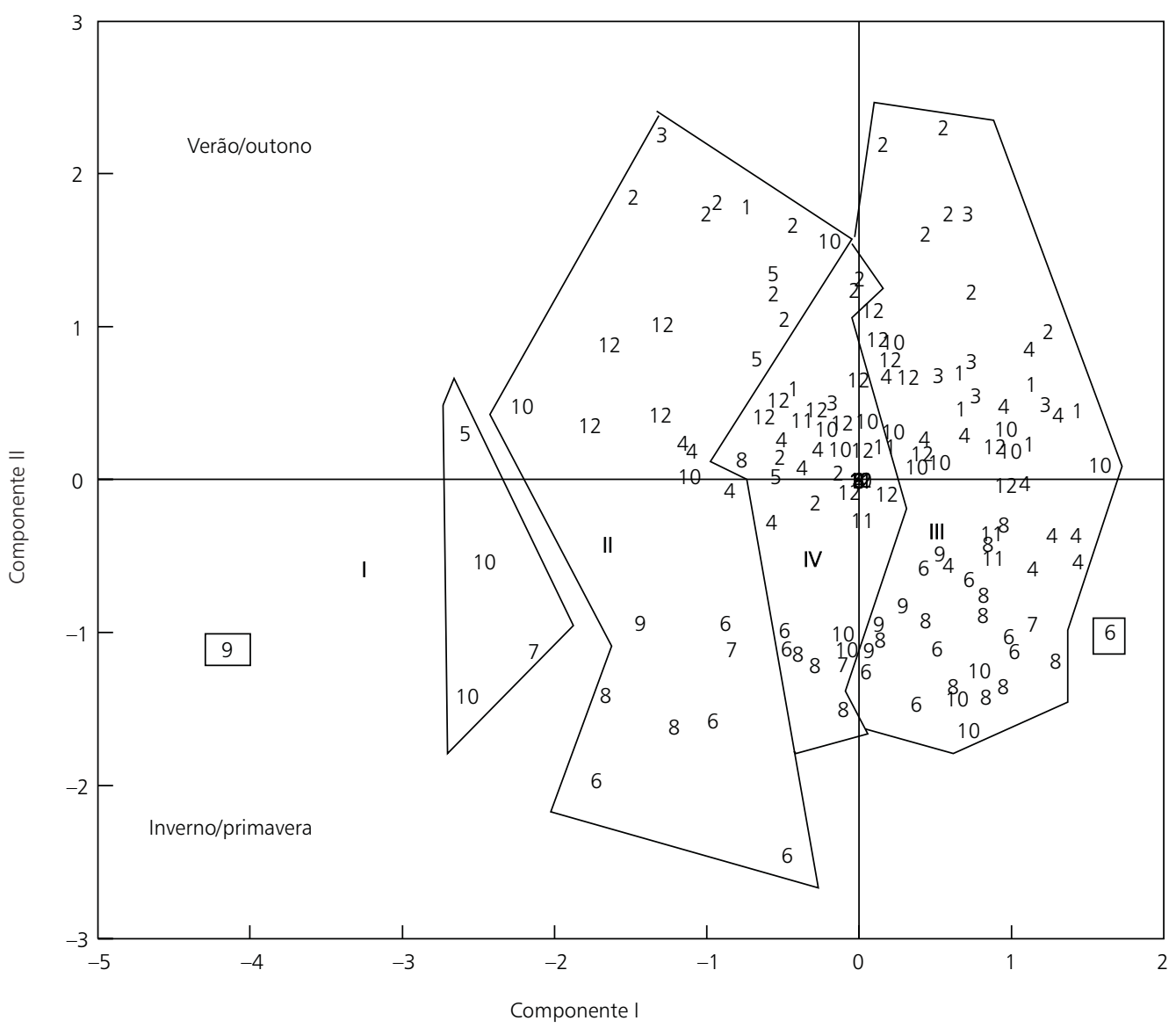

Fig. 4 - Diagrama de ordenação nos dois primeiros componentes principais para as amostras dos fatores ambientais, codificadas por mês, na Baía de Sepetiba, RJ. Grupos delimitados conforme análise de agrupamento.

TABELA 2

Componentes principais da abundância em número e peso das quatro espécies de bagres marinhos na Baía de Sepetiba, RJ.

\begin{tabular}{|c|c|c|c|}
\hline Variáveis & Componente I & Componente II & Componente III \\
\hline C. spixii $(\mathrm{N})$ & 0,16 & 0,88 & 0,19 \\
\hline C. spixii $(\mathrm{P})$ & 0,11 & 0,91 & 0,18 \\
\hline G. genidens $(\mathrm{N})$ & 0,76 & 0,44 & 0,16 \\
\hline G. genidens $(\mathrm{P})$ & 0,64 & 0,41 & 0,09 \\
\hline N. barba $(\mathrm{N})$ & 0,91 & 0,01 & 0,12 \\
\hline N. barba $(\mathrm{P})$ & 0,92 & 0,01 & 0,05 \\
\hline S. luniscutis $(\mathrm{N})$ & 0,15 & 0,21 & 0,93 \\
\hline S. luniscutis $(\mathrm{P})$ & 0,09 & 0,16 & 0,94 \\
\hline Autovalores & 3,87477 & 1,69998 & 1,14099 \\
\hline Variância explicada (\%) & 48,4 & 21,2 & 14,3 \\
\hline
\end{tabular}




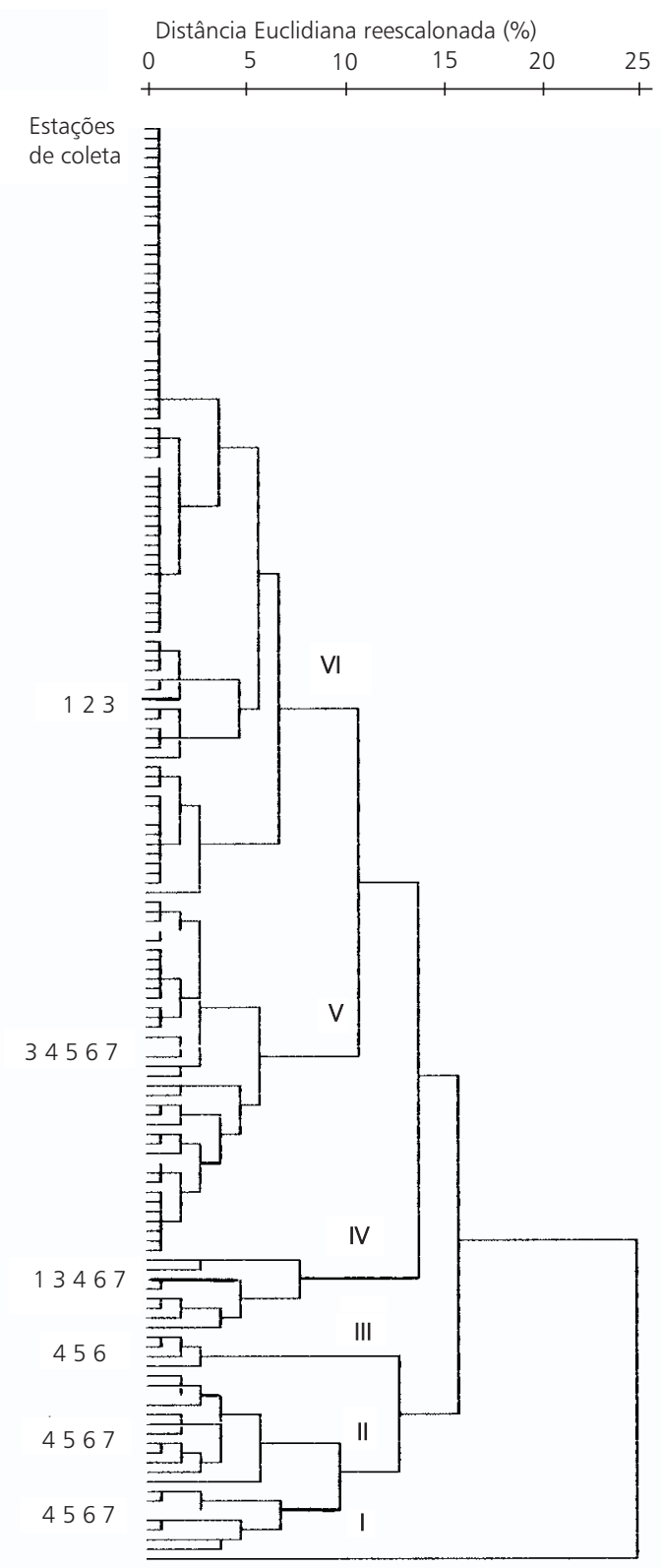

Fig. 5 - Agrupamento hierárquico da abundância das quatro espécies de bagres marinhos por estações de coleta na Baía de Sepetiba, RJ, entre 1993/1996. Legenda das estações conforme metodologia.

O diagrama dos Componentes I e II das amostragens codificadas pelas estações de coleta (Fig. 6), separou-as espacialmente ao longo do Componente I, situando de um lado as estações da zona interna (Grupos I, II e III da análise de agrupamento) e do outro lado uma predominância das estações da zona externa (Grupo VI da análise de agrupamento). O Componente II separou, com menor precisão, as estações de coleta da zona externa (Grupo
VI) em oposição as demais estações de coleta. As coordenadas negativas de ambos os eixos da Análise de Componentes Principais, em que se encontram a maioria das estações da zona externa (Grupo VI), apresentaram uma separação espacial em relação aos outros grupos (zona interna). Esse mesmo diagrama codificado pelos meses de amostragem não apresentou ao longo do Componente I e, também, do Componente II um padrão sazonal definido. 


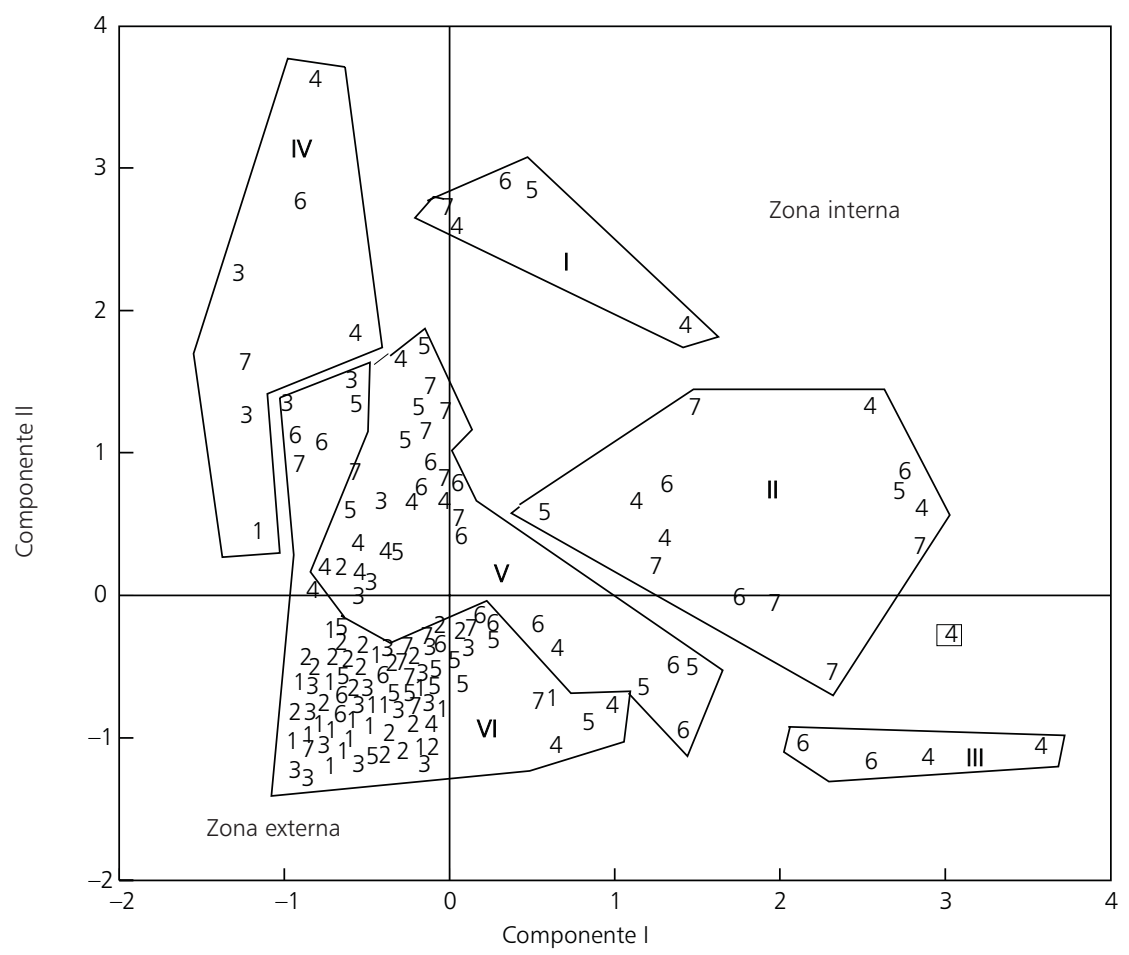

Fig. 6 - Diagrama de ordenação nos dois primeiros componentes principais para as amostras de abundância relativa de peixes, codificadas por estação de coleta na Baía de Sepetiba, RJ. Grupos delimitados conforme análise de agrupamento.

A comparação das médias de CPUEs e biomassas das quatro espécies de bagres marinhos e dos fatores ambientais, entre os grupos formados pela análise de agrupamento, é apresentada na Tabela 3, com as quatro espécies apresentando diferenças significativas em abundâncias $(\mathrm{p}<0,05)$. C. spixii apresentou maior CPUE nos Grupos IV e I e maior biomassa nos Grupos IV, I e II. G. genidens apresentou maior CPUE nos Grupos I e II, e maior biomassa nos Grupos I, III, II e V. N. barba teve maior CPUE e biomassa nos Grupos III, II e I e S. luniscutis, nos Grupos II, IV e V. Os Grupos IV, VI e V apresentaram maior salinidade de superfície e o Grupo VI, maior profundidade. A abundância das espécies e dos fatores ambientais que apresentaram valores significantemente mais elevados são sumarizados na Tabela 4.

$N$. barba parece estar restrito à zona interna, principalmente nas estações de coleta de menor profundidade e menor salinidade de superfície (Grupos I, II e III). C. spixii apresentou distribuição mais ampla na zona interna do que $N$. barba, ocorrendo em estações de menor profundidade (Grupo II), e também nas estações de maior sa- linidade da zona interna (Grupo IV). G. genidens apresentou uma ocorrência mais ampla na zona interna do que as últimas espécies (Grupos I, II, III e V), ocorrendo também em estações da zona externa (Grupo V). S. luniscutis parece apresentar distribuição mais ampla em relação às demais espécies, ocorrendo na zona interna e externa (Grupos II, IV e V).

\section{DISCUSSÃO}

A coexistência dos bagres marinhos na Baía de Sepetiba, com alguma indicação de separação espacial entre as quatro espécies, parece ser a estratégia desenvolvida por esse grupo de peixes para utilizarem a área em elevadas abundâncias. Técnicas multivariadas determinaram um padrão espacial definido de maiores transparências, profundidades e salinidades nas estações de coleta da zona externa da Baía, e um padrão temporal determinado pela temperatura.

Em relação à abundância dos bagres, observou-se um padrão espacial diferenciado entre as espécies e nenhum padrão em relação à sazonalidade, com maiores abundâncias nas baixas profun- 
didades, transparências e salinidades. $N$. $b a r b a$ apresentou distribuição mais restrita à zona interna da Baía, basicamente, nas proximidades da embocadura do Rio Guandú, enquanto C. spixii apresentou maior ocorrência na zona interna, com maiores abundâncias tanto no Fundo da Baía como na embocadura do Rio Guandú. G. genidens apresentou uma ampla distribuição na zona interna, enquanto $S$. luniscutis ocorreu em elevadas abundâncias, tanto na zona interna quanto na zona externa da Baía.

Araújo (1988) reportou que $N$. barba permanece no estuário da Lagoa dos Patos durante os dois primeiros anos de vida, juntando-se aos adultos posteriormente e migrando para o mar. Tal padrão não foi verificado no presente caso, provavelmente, devido a menor ocorrência dessa espécie na região Sudeste. Mishima \& Tanji (1983a) também registraram a baixa ocorrência de $N$. barba no complexo lagunar de Cananéia, confirmando que esta espécie apresenta maior ocorrência na região Sul.
Mishima \& Tanji (1983b) concluíram que as espécies de bagres mais abundantes no complexo lagunar de Cananéia apresentaram hábitat nitidamente separados, ocorrendo em áreas de profundidades diferentes. C. spixii e S. luniscutis foram mais abundantes nos canais, com profundidade média de $9 \mathrm{~m}$ e $G$. genidens e $N$. barba nos baixios, com profundidade média de $3 \mathrm{~m}$. Na Baía de Sepetiba, apenas $S$. luniscutis distribuiu-se com elevadas abundâncias relativas nas áreas mais profundas.

Lara-Dominguez et al. (1981) citam que a salinidade influencia a abundância dos bagres marinhos. Araújo (1988) encontrou baixa correlação, embora significativa, entre a abundância dos bagres marinhos com a temperatura e a salinidade, sendo que as três espécies de bagres estudadas ( $G$. genidens, $N$. barba e $N$. planifrons) ocorreram em elevadas abundâncias em uma grande amplitude de variação desses fatores ambientais.

TABELA 3

Valores de $\mathrm{F}$ e diferenças significativas ( $\mathrm{P}<\mathbf{0 , 0 5}$, ANOVA) entre os seis diferentes grupos formados pela análise de agrupamento, de abundância numérica e em peso, de quatro espécies de bagres marinhos na Baía de Sepetiba, RJ, através do Teste de Tukey para comparação das médias. Médias das Variáveis entre parênteses.

\begin{tabular}{|c|c|c|c|c|}
\hline & $\mathbf{F}$ & & upo & \\
\hline \multirow[t]{2}{*}{ C. spixii $(\mathrm{N})$} & \multirow[t]{2}{*}{$50,7^{* *}$} & IV I & $>$ & VI \\
\hline & & $(121-790)$ & & $(0-0,7)$ \\
\hline \multirow[t]{2}{*}{ C. spixii (P) } & \multirow[t]{2}{*}{$39,9^{* *}$} & IV I II & $>$ & V VI III \\
\hline & & $(1132-12564,2)$ & & $(0-203)$ \\
\hline \multirow[t]{2}{*}{ G. genidens $(\mathrm{N})$} & \multirow[t]{2}{*}{$44,9 * *$} & I II & $>$ & IV VI \\
\hline & & $(159-376,5)$ & & $(2-4)$ \\
\hline \multirow[t]{2}{*}{ G. genidens $(\mathrm{P})$} & \multirow[t]{2}{*}{$35,5^{* *}$} & $\begin{array}{llll}\text { I } & \text { III } & \text { II } & \text { V }\end{array}$ & $>$ & IV VI \\
\hline & & $(1314-8700)$ & & $(143-207)$ \\
\hline \multirow[t]{2}{*}{ N. barba $(\mathrm{N})$} & \multirow[t]{2}{*}{$50,0^{* *}$} & III II I & $>$ & V VI IV \\
\hline & & $(4,2-28,7)$ & & $(0-0,7)$ \\
\hline \multirow[t]{2}{*}{ N. barba $(\mathrm{P})$} & \multirow[t]{2}{*}{$63,5^{* *}$} & III $\quad$ II $\quad$ I & & $\begin{array}{lll} & \text { VI } & \text { IV }\end{array}$ \\
\hline & & $(147,8-2062)$ & & $(0-14)$ \\
\hline \multirow[t]{2}{*}{ S. luniscutis $(\mathrm{N})$} & \multirow[t]{2}{*}{$25,0 * *$} & $\begin{array}{lll}\text { II } & \text { IV } & \text { V }\end{array}$ & & $\begin{array}{lll}\text { VI } & \text { I } & \text { III }\end{array}$ \\
\hline & & $(38,6-20,2)$ & & $(0-3,58)$ \\
\hline \multirow[t]{2}{*}{ S. luniscutis $(\mathrm{P})$} & \multirow[t]{2}{*}{$41,51 * *$} & IV II $\mathrm{V}$ & $>$ & $\begin{array}{lll}\text { I } & \text { VI } & \text { III }\end{array}$ \\
\hline & & $(1723-3436)$ & & $(0-17,8)$ \\
\hline \multirow[t]{2}{*}{$\overline{\text { Salinidade superfície }}$} & \multirow[t]{2}{*}{$3,16^{* *}$} & $\begin{array}{lll}\text { IV } & \text { VI } & \text { V }\end{array}$ & $>$ & III \\
\hline & & $(29,8-31,1)$ & & $(22,2)$ \\
\hline \multirow[t]{2}{*}{ Profundidade } & \multirow[t]{2}{*}{$2,5^{*}$} & VI & $>$ & II \\
\hline & & $(9,0)$ & & $(5,2)$ \\
\hline
\end{tabular}


TABELA 4

Estações de coleta (zonas interna e externa), meses, espécies e fatores ambientais nos grupos formados pela análise de agrupamento.

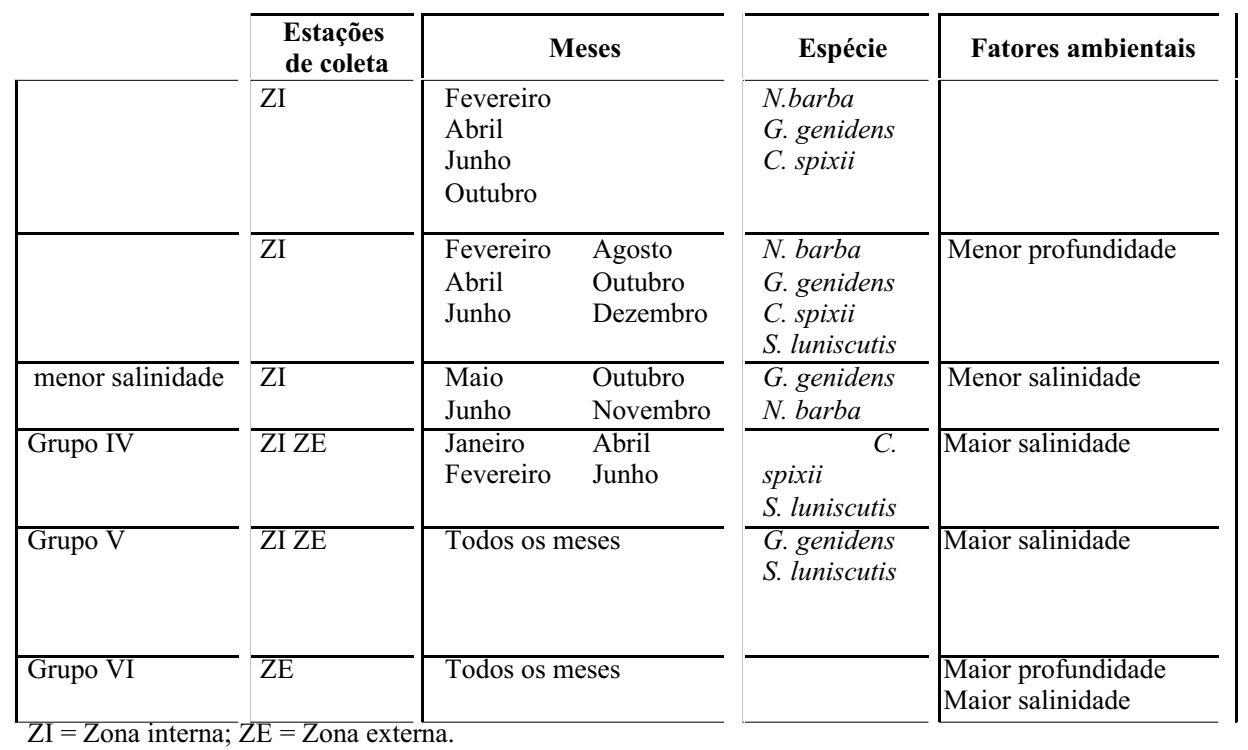

No estuário de Cananéia, C. spixii, G. genidens e $S$. luniscutis também ocorreram em amplas variações de salinidade $(0,1 \%$ o a $33 \%$ o), enquanto jovens de $N$. barba, B. bagre e B. marinus concentraram-se em salinidades mais elevadas $(15 \% \mathrm{o}$ a $33 \%$ o). Isso provavelmente foi devido aos adultos dessas espécies viverem em mar aberto (Mishima \& Tanji, 1981).

Variações temporais na abundância das populações de ambientes em que os fatores ambientais são relativamente estáveis, situados em regiões limítrofes da zona tropical, como a Baía de Sepetiba, parecem ser menos evidentes do que em regiões temperadas. Nestas últimas, a variação cíclica dos fatores ambientais contribui para o estabelecimento de um padrão sazonal definido. Cruz-Filho (1995) observou que os peixes mais abundantes nessa Baía, incluindo G. genidens e C. spixii, apresentaram, em sua maioria, padrões sazonais pouco definidos.

Padrões sazonais de ocorrência para bagres marinhos em regiões estuarinas foram reportados por vários autores como relevante no ciclo de vida desses peixes (Reis, 1982; Araújo, 1988; Mishima \& Tanji, 1981; Yañez-Aracibia et al., 1976). Segundo Lara-Dominguez et al. (1981), a sazonalidade dos bagres marinhos parece ser controlada por fatores abióticos, principalmente temperatura e salinidade. A estabilidade dos fatores ambientais na Baía de Sepetiba pode estar explicando a baixa sazonalidade dos bagres marinhos. Em estuários tropicais desenvolvem-se relações interespecíficas que resultam na utilização diferenciada do ambiente (Margalef, 1977), ressaltando-se a competição entre juvenis por áreas protegidas e ricas em alimento, o que gera a separação do uso do espaço.

A grande abundância de peixes da família Ariidae na Baía de Sepetiba caracteriza a importância ecológica deste ambiente no ciclo de vida dessas espécies. O padrão espacial foi melhor definido que o temporal, com indicações de separação espacial como estratégia de coexistência desse grupo de peixes no interior desse ambiente costeiro tropical semi-aberto, com as maiores abundâncias nas zonas com menores profundidades, transparências e salinidades.

\section{REFERÊNCIAS BIBLIOGRÁFICAS}

ANDREATA, J. V., BARBIERI, L. R. R., SEBILIA, A. S. B., SILVA, M. H. C. \& SANTOS, R. P., 1989, A list of Marapendi Lagoon fishes, Rio de Janeiro, Brazil. Atlântica, 11: 5-17.

ARAÚJO, F. G., 1988, Abundância relativa, distribuição e movimentos sazonais de bagres marinhos (SILURIFORMES, ARIIDAE) no estuário do Lagoa dos Patos, RS. Rev. Bras. de Zool., 5(4): 509-543. 
COSTA, R. N. L. T. R., 1992, Pensar o mar para poder pescar: o espaço da pesca de litoral na Baía de Sepetiba, RJ. Dissertação de Mestrado. Pós-Graduação em Geografia da UFRJ, 181p.

CRAIG, I. D. H., 1980, Contribution to the Knowledge of the Coastal Fish Species of the Peruibe Region. Part I: The Ariidae. Rev. Brasil. Biol., 40(4): 755-758.

CRUZ-FILHO, A. G., 1995, Variações espaciais e temporais na comunidade de peixes da Baía de Sepetiba, RJ. Dissertação de Mestrado. Instituto de Florestas, UFRRJ, Curso de Mestrado em Ciências Ambientais e Florestais, Rio de Janeiro, 99p.

DHN, 1984, Baía de Sepetiba. Carta Naútica $N^{o} 1621$. Diretoria de Hidrografia e Navegação, Rio de Janeiro.

FIGUEIREDO, J. L. \& MENEZES, N. A., 1978, Manual de Peixes Marinhos do Sudeste do Brasil. II Teleostei (1). Universidade de São Paulo, Museu de Zoologia, 110p.

GAUCH JR., H. H., 1982, Multivariate Analysis. Heinemann Educational Books, 2를. ed., London, 210p.

LARA-DOMINGUEZ, A. L., YAÑEZ-ARACIBIA, A. \& LINHARES, F. A., 1981, Biologia e ecologia del bagre Arius melanopus Gunther en Laguna dos Térmitos, sur del Golfo do México (Pisces:Ariidae). An. Centro de Ciências del Mar y Limnol., Univ. Auton., México, 8(1): 267-304.

LEGENDRE, L. \& LEGENDRE, P., 1983, Numerical Ecology. New York, Elsevier, 420p.

MARDIA, K. V., KENT, J. T. \& BIBBY, J. M., 1979, Multivariate Analysis. Academic Press, London, 521p.

MARGALEF, R., 1977, Ecologia. Barcelona, Ed. Omega. $951 \mathrm{p}$.
MISHIMA, D. \& TANJI, S., 1981, Distribuição geográfica dos bagres marinhos (OSTEICHTHYES, ARIIDAE) no complexo estuarino lagunar de Cananéia $\left(25^{\circ} \mathrm{S}, 48^{\circ} \mathrm{W}\right)$. Bol. Inst. Pesca., 8: 157-172.

MISHIMA, M. \& TANJI, S., 1983a, Maturação e desova dos bagres marinhos (OSTEICHTHYES, ARIIDAE) do complexo lagunar de Cananéia $\left(25^{\circ} \mathrm{S}, 48^{\circ} \mathrm{W}\right)$. Bol. Inst. Pesca, 10: $129-141$.

MISHIMA, M. \& TANJI, S., 1983b, Fatores ambientais relacionados à distribuição e abundância de bagres marinhos (OSTEICHTHYES, ARIIDAE) no complexo estuarino lagunar de Cananéia $\left(25^{\circ} \mathrm{S} ; 48^{\circ} \mathrm{W}\right)$. Bol. Inst. Pesca, 10 : 17-27.

MOYLE, P. B. \& CECH-JR, J. J., 1988, Fishes - An Introduction to Ichthyology. Prentice Hall, 2 $2^{\underline{a}}$ ed. Englewood Clifs, New Jersey, 559p.

REIS, E. G., 1986, A pesca artesanal de bagres marinhos (SILURIFORMES, ARIIDAE) no Estuário da Lagoa dos Patos (RS). Documentos Técnicos, 05, FURG, Rio Grande do Sul, 22p.

SOKAL, R. P. \& ROHLF, F. J., 1981, Biometry: The Principles and Pratice of Statistcs in Biological Research. W. H. Freman and CO., 2ae ed., San Francisco, $776 \mathrm{p}$.

YAÑEZ-ARACIBIA, A., CURIEL-GOMEZ, J. \& YAÑEZ, V. L., 1976, Prospección biológica y ecológica del bagre marino Galeichthys cearulensis (Guntter) en el sistema lagunar costero Guerrero, México (Pisces:Ariidae). An Centro de Ciencias del Mar y Limnol., Univ. Auton. México, 3(1): 125-180. 